\title{
Severe calciphylaxis in a patient with end stage renal disease
}

\begin{abstract}
A case of severe calciphylaxis in a patient with End Stage Renal Disease on peritoneal dialysis is presented. Diagnosis was based on medical history and clinical findings and was confirmed by skin biopsy. A multidisciplinary medical team was involved in the patient's management who was treated with intravenous sodium thiosulfate, intensified hemodialysis sessions, parathyroidectomy and surgical debridement. Calciphylaxis is a rare manifestation of chronic kidney disease, although non uremic causes have also been identified. The prognosis is generally poor. When confronting the disease, the physician does not stand on solid ground due to the lack of well designed treatment studies.
\end{abstract}

Volume 2 Issue 2 - 2015

\author{
Kyriakos loannou,Andreas Kousios \\ Department of Nephrology, Nicosia General Hospital, Cyprus
}

Correspondence: Kyriakos loannou, Department of Nephrology, Nicosia General Hospital, Cyprus. Tel +35722603759, Fax +35722604332,

Email kyr_ioannou@hotmail.com

Received: March 24, 2015 | Published: April 25, 2015

Keywords: calciphylaxis, calcific uremic arteriolopathy, sodium thiosulfate

Abbreviations: ESRD, end stage renal disease; CUA, calcific uremic arteriolopathy; SLE, systemic lupus erythematosus; CAPD, continuous ambulatory peritoneal dialysis; $\mathrm{HD}$, hemodialysis; $\mathrm{CVVH}$, continuous venovenous hemofiltration; $\mathrm{CKD}$, chronic kidney disease

\section{Introduction}

Calciphylaxis or Calcific Uremic Arteriolopathy (CUA) is a rare complication of Chronic Kidney Disease (CKD) with a high mortality rate; more than $50 \%$ of patients die within the first year. ${ }^{1}$ CUA affects small and medium-sized blood vessels that cause ischemic necrosis of the skin and subcutaneous fat. Clinically, it often presents with painful livedoid-like lesions, plaques and subcutaneous nodules that progress to necrotic ulcers with eschars predisposing the patients to lifethreatening infections. When a biopsy is performed the histological findings include medial arteriolar calcification, intimal hyperplasia and fibrosis. Acute and chronic calcifying septal panniculitis is the most common histological finding regardless the stage of the disease. ${ }^{2}$ Managing calciphylaxis is a demanding task and requires a multidisciplinary approach and close monitoring of the patient to prevent infection; sepsis being the most common cause of death. ${ }^{1}$ The lack of randomized control trials with regard to treatment options renders the therapeutic approach even more troublesome and the attending physicians face uncertainties and dilemmas.

\section{Case presentation}

We present the case of a 42-year-old woman with a history of Systemic Lupus Erythematosus (SLE) from the age of 18 and CKD that progressed to ESRD leading initially to a living non-related kidney transplantation at the age of 31 and followed by patient induction to Continuous Ambulatory Peritoneal Dialysis (CAPD) at the age of 38, due to failing graft. The patient was referred to our hospital with bilateral leg ulcers, initially described as painful erythematous plaques. Over the past months, her peritoneal dialysis clearance was inadequate and progressively she experienced very high levels of urea, but despite her doctors' recommendations, she had refused a switch to hemodialysis (HD). On examination, she was clearly cachectic, anxious and in extreme pain, but hemodynamically stable and afebrile. There were extensive ulcers on her legs with necrotic eschars (Figure 1). Laboratory results were notable for $\mathrm{Hb}=7,5 \mathrm{~g}$ / $\mathrm{dL}$, Urea $=260 \mathrm{mg} / \mathrm{dL}$, Creatinine $=9 \mathrm{mg} / \mathrm{dl}$, Total Calcium $=10,3 \mathrm{mg} /$ dl, Phosphate $=6 \mathrm{mg} / \mathrm{dL}$ and $\mathrm{iPTH}=680 \mathrm{pg} / \mathrm{ml}$. The clinical diagnosis was severe calciphylaxis, which was later confirmed by the results of a skin biopsy, demonstrating medial calcification of small vessels with intimal hyperplasia. Initially, she received supportive treatment with analgesics, blood transfusion, intravenous (IV) antibiotics (vancomycin, impipenem/cilastatin) and assessment by general and plastic surgeons for wound care. After extensive discussion with the patient for the need of intensive dialysis, a dual lumen catheter was inserted and she was started on daily, three hour hemodialysis sessions with low calcium $(1.25 \mathrm{mmol} / \mathrm{L})$ dialysate, followed by $25 \mathrm{mg}$ of sodium thiosulfate IV administration at the end of every HD session. She was also started on phosphate binders (sevelamer) and calcimimetics (cinacalcet) for better secondary hyperparathyroidism control. Whilst she had shown some improvement of her left leg ulcer, and despite the vigorous wound care and antibiotics use, she had developed severe infection of the right leg and concomitant sepsis (Figure 2) that finally led to amputation of her right leg below knee a month later,for life-saving. Following clinical improvement, the patient also underwent subtotal parathyroidectomy. She continued treatment with three weekly hemodiafiltration sessions and $25 \mathrm{mg}$ sodium thiosulfate IV administration post dialysis. After a total of six months hospitalization period, the CUA lesions on her left leg had completely resolved (Figure 3 ) and the patient was discharged with a plan to receive prosthetic limb rehabilitation.

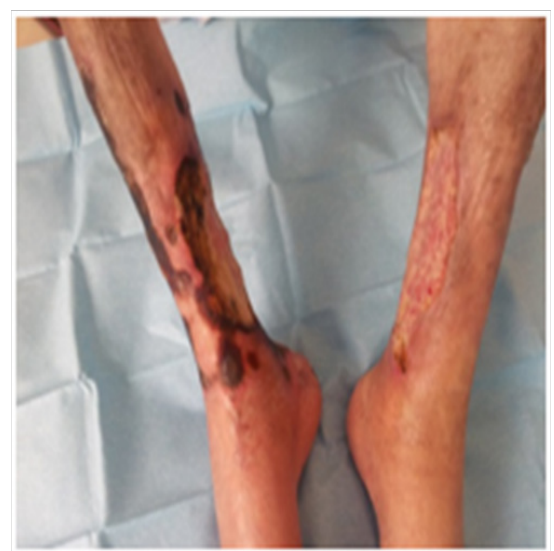

Figure I Extensive ulcers with necrotic eschars. 


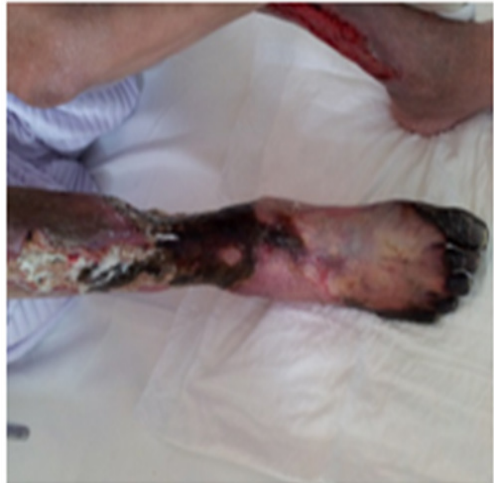

Figure 2 Severe infection of the right leg.

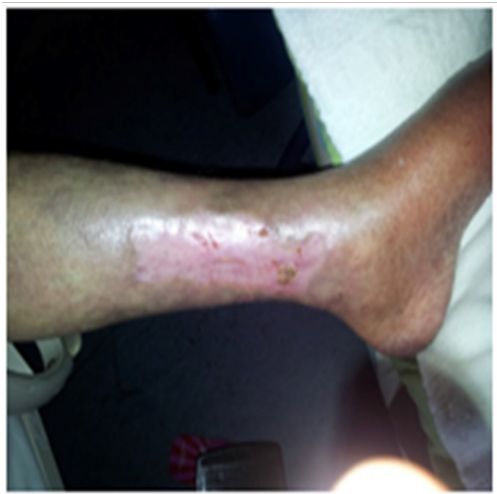

Figure $3 \mathrm{CUA}$ lesions on the left leg completely resolved.

\section{Discussion}

Despite the efforts to accurately report the incidence and prevalence of CUA, as made via registries (UK and German registry), there are still no robust data. The prevalence has been estimated to be less than $1 \%$ in dialysis patients, ${ }^{3}$ even though earlier studies have reported higher estimates. ${ }^{4}$ The oxymoron is that there is a considerable disproportion between published case reports or reviews and original work on CUA. ${ }^{5}$ It is important to note that non uremic calciphylaxis causes are also reported. ${ }^{6}$ The pathogenesis of the disease is complex and many questions remain unanswered. It seems that some conditions may predispose to the development of the CUA; chronic kidney disease being the most important among them. Nonetheless, CUA is a rare phenomenon among CKD patients. Therefore, a "second hit" or a "challenger" on an already "sensitized" patient may be superimposed, a fact that is in keeping with the abrupt onset of the disease. Many risk factors have been associated with the disease, although their exact role in the pathogenesis of CUA is not defined. These include female gender, diabetes, liver disease, obesity, hypoalbuminaemia, hyperphosphataemia, hyperparathyroidism, calcium and vitamin $\mathrm{D}$ analogue supplementation, warfarin and steroid use.,7 On the molecular level, a loss of balance between procalcification and anticalcification factors is critical for the development of CUA. For example, matrix Gla protein is a calcification inhibitor whose function depends on vitamin $\mathrm{K}$. Warfarin use or vitamin-K deficient patients suppress matrix Gla protein function causing vascular calcification. ${ }^{8}$

A wide range of treatment options are proposed for CUA, but none of them is based on prospective randomized trials. The aim is to provide adequate wound care, pain control, prevent infection and correct calcium, phosphorus and PTH abnormalities. Intensifying hemodialysis dose is another option proposed. Geurra et al., ${ }^{9}$ reported successful treatment of severe calciphylaxis with a combination of daily continuous venovenous hemofiltration $(\mathrm{CVVH})$ and intravenous sodium thiosulfate in an attempt to mobilize and remove deposited vascular calcium. ${ }^{9}$ Sodium thiosulfate administration is a promising therapeutic strategy with increasing publications of its use in case reports and case series. ${ }^{10,11}$ Sodium thiosulfate is a chelating agent used for cyanide intoxication with a documented efficacy for the treatment of recurrent urolithiasis. ${ }^{12}$ Its use for calciphylaxis treatment was initially reported in $2004 .{ }^{13}$ Although it is believed that sodium thiosulfate interferes with calcium phosphate crystal formation, how this compound acts on vascular calcification is largely unknown. ${ }^{14} \mathrm{We}$ are still in the dark with regard to the optimal dose of sodium thiosulfate and the duration of treatment. Parathyroidectomy is another widely discussed topic and an option for severe hyperparathyroidism, but the role of surgical intervention is unclear in borderline cases and if it is superior to treatment with calcimimetics. Cinacalcet might also have a preventive effect for the development of calciphylaxis when compared to placebo. ${ }^{15}$ Many other treatment options have been reported, as a part of a multilevel approach such as, vitamin K supplementation, use of bisphosphonates, hyperbaric oxygen therapy etc and it's up to the attending physician to evaluate their appropriateness in specific cases.

\section{Conclusions}

Calciphylaxis, despite its rarity as an entity, is a well known complication of chronic kidney disease. Although significant progress has been observed, many areas remain to be addressed regarding disease epidemiology, pathogenesis and more importantly, effective therapy and prevention. Sodium thiosulfate is a promising therapeutic option, while infection prevention and treatment is life-saving.

\section{Acknowledgements}

None.

\section{Conflict of interest}

The author declares no conflict of interest.

\section{References}

1. Weenig RH, Sewell LD, Davis MD, et al. Calciphylaxis: natural history, risk factor analysis, and outcome. J Am Acad Dermatol. 2007;56(4):569579 .

2. Essary LR, Wick MR. Cutaneous calciphylaxis. An under recognized clinicopathologic entity. Am J Clin Pathol. 2000;113(2):280-287.

3. Brandenburg VM, Cozzolino M, Ketteler M. Calciphylaxis: a still unmet challenge. J Nephrol. 2011;24(2):142-148.

4. Angelis M, Wong LL, Myers SA, et al. Calciphylaxis in patients on hemodialysis: a prevalence study. Surgery. 1997;122(6):1083-1089.

5. Brandenburg VM, Cozzolino M, Mazzaferro S. Calcific Uremic Arteriolopathy:A Call for Action. Semin Nephrol. 2014;34(6):641-647.

6. Nigwekar SU, Wolf M, Sterns RH, et al. Calciphylaxis from nonuremic causes: a systematic review. Clin J Am Soc Nephrol. 2008;3(4):11391143.

7. Hayashi M, Takamatsu I, Kanno Y, et al. A case-control study of calciphylaxis in Japanese end-stage renal disease patients. Nephrol Dial Transplant. 2012;27(4):1580-1584.

8. Krueger T, Westenfeld R, Schurgers L, et al. Coagulation meets calcification: the vitamin K system. Int J Artif Organs. 2009;32(2):67-74. 
9. Geurra G, Shah RC, Ross AE. Rapid resolution of calciphylaxis with intravenous sodium thiosulfate and continuous venovenous haemofiltration using low calcium replacement fluid:case report. Nephrol Dial Transplant. 2005;20(6):1260-1262.

10. Zitt E, Konig M, Vychytil A, et al. Use of sodium thiosulphate in a multi-interventional setting for the treatment of calciphylaxis in dialysis patients. Nephrol Dial Transplant. 2013;28(5):1232-1240.

11. Nigwekar SU, Brunelli SM, Meade D, et al. Sodium thiosulfate therapy for calcific uremic arteriolopathy. Clin J Am Soc Nephrol. 2013;8(7):1162-1170
12. Yatzidis H. Successful sodium thiosulphate treatment for recurrent calcium urolithiasis. Clin Nephrol. 1985;23(2):63-67.

13. Cicone JS, Petronis JB, Embert CD, et al. Successful treatment of calciphylaxis with intravenous sodium thiosulfate. Am J Kidney Dis. 2004;43(6):1104-1108.

14. O’Neill WC, Hardcastle KI. The chemistry of thiosulfate and vascular calcification. Nephrol Dial Transplant. 2012;27(2):521-526.

15. EVOLVE Trial Investigators, Chertow GM, Block GA, et al. Effect of cinacalcet on cardiovascular disease in patients undergoing dialysis. $N$ Engl J Med. 2012;367(26):2482-2494. 